\title{
Dynamic compliance in flow-controlled ventilation
}

\author{
Dietmar Enk ${ }^{1}$, Julia Abram² ${ }^{2 *}$, Patrick Spraider ${ }^{2}$ and Tom Barnes ${ }^{3}$
}

${ }^{*}$ Correspondence:

julia.abram@i-med.ac.at

${ }^{2}$ Department

of Anaesthesiology

and Intensive Care

Medicine, Medical University

of Innsbruck, Innsbruck,

Austria

Full list of author information

is available at the end of the article
The recent paper by Wittenstein et al. "Comparative effects of flow- vs. volume-controlled one-lung ventilation on gas exchange and respiratory system mechanics in pigs" [1] contains some intriguing observations we would like to discuss.

\section{Alveolar pressure amplitude}

In flow-controlled ventilation (FCV), the gas flow is constant during both inspiration and expiration $[2,3]$. This significantly differs from volume-controlled ventilation (VCV) where inspiratory flow is constant, but exhalation is passively driven by lung-chest elasticity resulting in a decelerating flow profile. Furthermore, in contrast to VCV (and any other ventilation mode) in FCV gas is always moving either into or out of the lungs without any pause phases in an accurately controlled way. This causes a continuous pressure drop across the airway resistance. Consequently, during inspiration tracheal pressure must be higher than alveolar pressure, whereas during expiration the opposite pertains. The alveolar driving pressure $(\Delta P)$ in FCV is therefore lower than the measured tracheal $\Delta P$.

Compliance (which necessarily means dynamic compliance considering the nature of FCV) calculated from tracheal $\Delta P$ will lead to an underestimation of actual (alveolar) lung compliance because tracheal $\Delta P$ is higher than the alveolar pressure swing. Figure 1 shows how it is possible to estimate the difference between tracheal $\Delta P$ and aggregate alveolar pressure swing using the measured airway resistance reported by Wittenstein et al. [1] for FCV. The calculated difference between the two pressures (partially) accounts for the difference of the compliance in both groups of the Wittenstein study. Using alveolar rather than tracheal $\Delta P$ for the calculation of the dynamic compliance therefore results in similar compliance in both groups.

\section{Dynamic compliance measurement}

Gas exchange in mechanical ventilation is strongly related to dynamic compliance. If a larger volume of respiratory gas is shifted at the same compliance pressure (i.e., the part of the total pressure distending the alveolar periphery), alveolar gas exchange/turnover improves. Assuming the ventilated compartments of the lungs are perfused, so carbon dioxide is delivered, any higher alveolar gas exchange/turnover should result in increased author(s) and the source, provide a link to the Creative Commons licence, and indicate if changes were made. The images or other third party material in this article are included in the article's Creative Commons licence, unless indicated otherwise in a credit line to the material. If material is not included in the article's Creative Commons licence and your intended use is not permitted by statutory regulation or exceeds the permitted use, you will need to obtain permission directly from the copyright holder. To view a copy of this licence, visit http:// creativecommons.org/licenses/by/4.0/. 


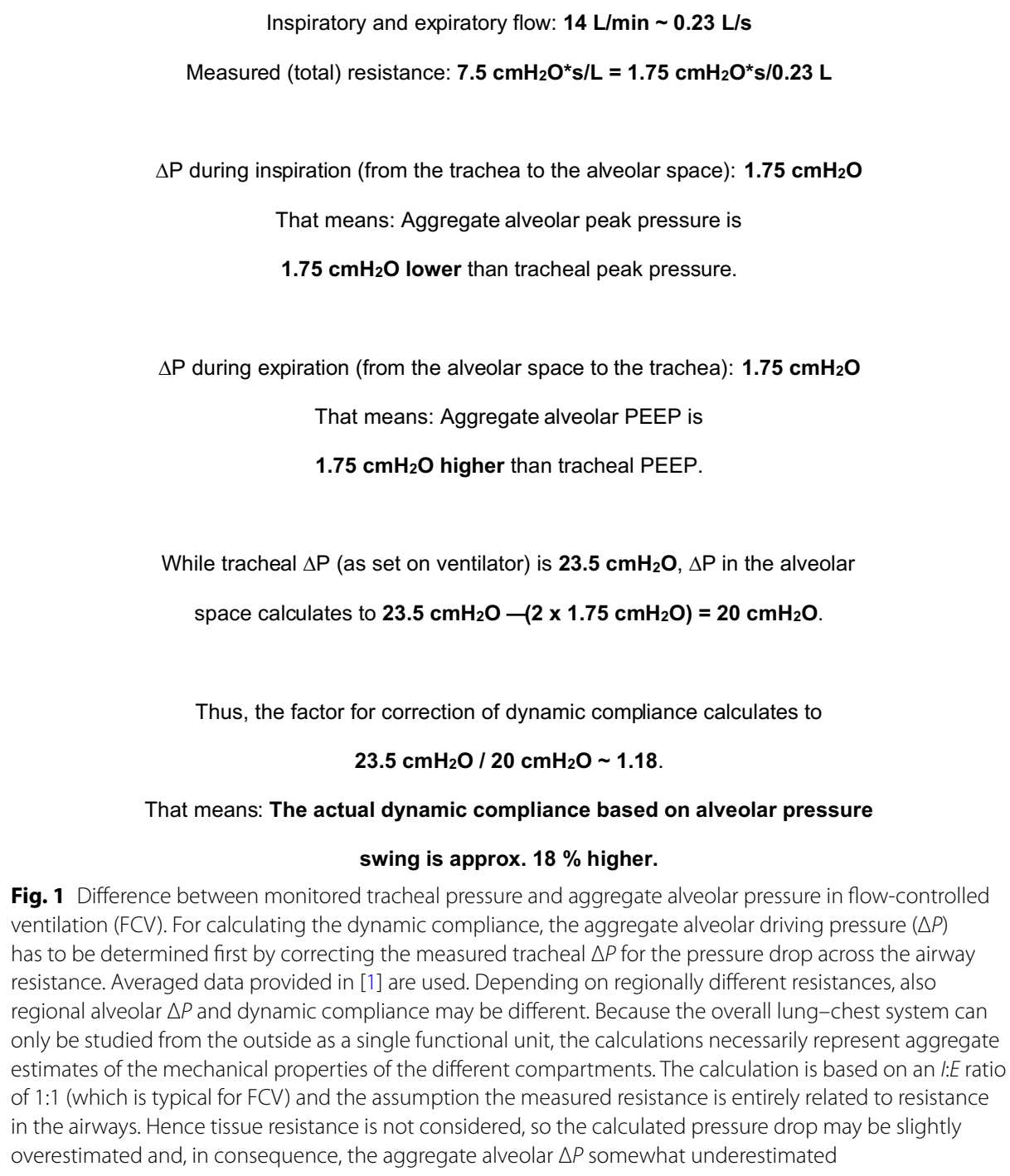

Fig. 1 Difference between monitored tracheal pressure and aggregate alveolar pressure in flow-controlled ventilation (FCV). For calculating the dynamic compliance, the aggregate alveolar driving pressure $(\triangle P)$ has to be determined first by correcting the measured tracheal $\triangle P$ for the pressure drop across the airway resistance. Averaged data provided in [1] are used. Depending on regionally different resistances, also regional alveolar $\triangle P$ and dynamic compliance may be different. Because the overall lung-chest system can only be studied from the outside as a single functional unit, the calculations necessarily represent aggregate estimates of the mechanical properties of the different compartments. The calculation is based on an I:E ratio of 1:1 (which is typical for FCV) and the assumption the measured resistance is entirely related to resistance in the airways. Hence tissue resistance is not considered, so the calculated pressure drop may be slightly overestimated and, in consequence, the aggregate alveolar $\triangle P$ somewhat underestimated

carbon dioxide elimination. Wittenstein et al. compared FCV with VCV during one-lung ventilation (OLV) in hypovolemic and normovolemic pigs. They reported significantly better carbon dioxide elimination with FCV in normovolaemia, but substantially lower compliance-this seems counterintuitive.

Further, they reported an airway resistance of approx. $8 \mathrm{cmH}_{2} \mathrm{O}^{*} \mathrm{~s} / \mathrm{L}$ with FCV but approx. $34 \mathrm{cmH}_{2} \mathrm{O}^{*} \mathrm{~s} / \mathrm{L}$ with $\mathrm{VCV}-$ more than four times larger. Even taking into account the difference in flows $(14 \mathrm{~L} / \mathrm{min}$ in FCV vs. $24 \mathrm{~L} / \mathrm{min}$ in VCV) and the use of a double-lumen tube with a small inner diameter as a prerequisite to perform OLV, this vast difference is surprising. In a similar double-lumen tube our own measurements show a pressure drop of $2.5 \mathrm{cmH}_{2} \mathrm{O}$ at a flow of $24 \mathrm{~L} / \mathrm{min}$ across the bronchial lumen (= resistance of $6.25 \mathrm{cmH}_{2} \mathrm{O} * \mathrm{~s} / \mathrm{L}$ ). Obviously, this cannot explain the large difference in airway resistance between $\mathrm{VCV}$ and FCV.

To compare the dynamic compliance in FCV (which is calculated by the ventilator based on bronchial pressure measurements) with dynamic compliance in VCV, 
Wittenstein et al. had to convert the airway pressure data measured proximally of the bronchial lumen of the double-lumen tube into bronchial values using measurements of proximal airway pressure, flow, and tube Rohrer resistance. Systematic error in any of these measurements (e.g., differing flow conditions between the Rohrer resistance determination and the experiment) could cause differences between measured and actual driving pressure which may have significant effect on measured compliance, resistance, and calculated mechanical power (e.g., with a tidal volume of $220 \mathrm{~mL}$ at $11 \mathrm{~mL} / \mathrm{cmH}_{2} \mathrm{O}$ compliance, only $2 \mathrm{cmH}_{2} \mathrm{O}$ difference translates to $10 \%$ change in measured compliance). If the resistive pressure (i.e., the part of the total pressure needed to overcome resistance) is falsely high in VCV, compliance pressure amplitude will be underestimated and thus dynamic compliance (or aggregate alveolar dynamic compliance as provided for FCV in this letter) overestimated. Furthermore, the energy applied to and stored in the elastic lung tissue (i.e., elastic mechanical power) in VCV will be underestimated.

\section{Effects of FCV}

Because of the constant flow used, FCV allows accurate measurement of relative pressure swings and delivered volumes. It offers a more individualized approach to ventilation, allowing compliance-guided setting of both positive end-expiratory pressure (PEEP) and peak pressure. In our experiments, it improved lung aeration homogeneity and gas exchange efficiency without detectable regional overinflation [4]. In contrast to the fixed FCV ventilator settings used in the study of Wittenstein et al., this approach may be also applicable in OLV, possibly further reducing respiratory rate and dead space ventilation while ventilating at substantially lower levels of mechanical power and dissipated energy compared to conventional ventilation modes.

Acknowledgements

Not applicable.

Authors' contributions

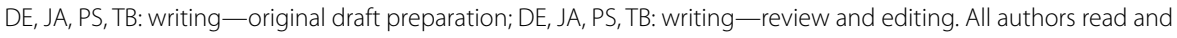
approved the final manuscript.

Funding

Not applicable.

Availability of data and materials

Not applicable.

\section{Declarations}

Ethics approval and consent to participate

Not applicable.

Consent for publication

Not applicable.

Competing interests

D. Enk: inventor of EVA and FCV technology (Ventrain, Tritube, Evone), royalties for EVA and FCV technology (Ventrain, Tritube, Evone), patent applications on minimizing dissipated energy and on calculating and displaying dissipated energy, (paid) consultant to Ventinova Medical. T. Barnes: patent application on calculating and displaying dissipated energy, (paid) consultant to Ventinova Medical.

\section{Author details}

${ }^{1}$ Faculty of Medicine, University of Münster, Münster, Germany. ${ }^{2}$ Department of Anaesthesiology and Intensive Care Medicine, Medical University of Innsbruck, Innsbruck, Austria. ${ }^{3}$ University of Greenwich, London, UK. 
Received: 12 March 2021 Accepted: 28 April 2021

Published online: 31 May 2021

\section{References}

1. Wittenstein J, Scharffenberg M, Ran X et al (2020) Comparative effects of flow- vs. volume-controlled one-lung ventilation on gas exchange and respiratory system mechanics in pigs. Intensive Care Med Exp 8(Suppl1):24

2. Barnes T, van AsseldonkT, Enk D (2018) Minimisation of dissipated energy in the airways during mechanical ventilation by using constant inspiratory and expiratory flows-flow-controlled ventilation (FCV). Med Hypotheses 121:167-176

3. Barnes T, Enk D (2019) Ventilation for low dissipated energy achieved using flow control during both inspiration and expiration. Trends Anaesth Crit Care 24(2):5-12

4. Spraider P, Martini J, Abram J et al (2020) Individualized flow-controlled ventilation compared to best clinical practice pressure-controlled ventilation: a prospective randomized porcine study. Crit Care 24(1):662

\section{Publisher's Note}

Springer Nature remains neutral with regard to jurisdictional claims in published maps and institutional affiliations.

\section{Submit your manuscript to a SpringerOpen ${ }^{\circ}$} journal and benefit from:

- Convenient online submission

- Rigorous peer review

- Open access: articles freely available online

- High visibility within the field

Retaining the copyright to your article

Submit your next manuscript at $\boldsymbol{\nabla}$ springeropen.com 